\title{
IRONIA E SUSPENSÃo TELEOLÓGICA DO GERAL EM SOREN KIERKEGAARD
}

\author{
Diogo Alves da Conceição Santana \\ Universidade do Estado do Rio de Janeiro (UERJ)
}

\begin{abstract}
Resumo: Segundo Soren Kierkegaard a moral identificando-se ao geral, por sua vez, corresponde ao divino, posição reconhecidamente hegeliana. 0 dever torna-se então o limite axiomático por onde 0 indivíduo se relaciona com Deus. Contudo, relacionar-se com a norma estabelece uma diferença qualitativa, tornando a relação uma falsificação, posto que não há equivalência entre Deus e a norma geral. Por outro lado, o indivíduo, ao se relacionar com o geral, também se perde como indivíduo. A alteridade em relação ao geral torna-se então a condição tanto para uma efetiva relação com Deus, como para uma relação do indivíduo consigo mesmo. Essa alteridade é compreendida por Kierkegaard como uma suspensão teleológica e posteriormente uma ressignificação das categorias como moralidade, dever e divino. 0 político, a partir de uma perspectiva hegeliana, atravessa essa relação com o geral, e por isso mesmo, é ambicionado pelo projeto de suspensão teleológica de Soren Kierkegaard. Suspensão teleológica que para o filósofo dinamarquês é reconhecida como ironia. Para tanto, na determinação de seu conceito de ironia, evoca a personalidade de Sócrates. É inevitável uma designação pontual da relação irônica entre tal personalidade com o Estado e o político. A personalidade de Sócrates evoca, assim, ironicamente, uma oposição, não apenas entre objetividade e subjetividade, exterior e 0 interior, contudo, também, entre o social enquanto relação espontânea e ocasional entre os indivíduos e 0 político enquanto instrumento de coesão para a formação da multidão. Partindo da relação entre Sócrates e 0 Estado grego, apontado por Kierkegaard como irônica, e reconhecendo nessa relação uma suspensão teleológica, o presente trabalho procura estabelecer os critérios indicados por Kierkegaard para tal determinação.
\end{abstract}

Palavras-chaves: Kierkegaard. Ironia. Estado.

\footnotetext{
${ }^{1}$ Graduando em filosofia. Email: diogosantana45@yahoo.com.br
} 
Irony and teleological suspension of the general in Soren Kierkegaard

\begin{abstract}
According to Soren Kierkegaard the morality identifying itself to the general, in turn, corresponds to the divine, admittedly Hegelian position. Duty then becomes the axiomatic limit whereby the individual relates to God. However, relating to the norm establishes a qualitative difference, making the relation a falsification, since there is no equivalence between God and the general norm. On the other hand, the individual in relating to the general also loses himself as an individual. The alterity in relation to the general then becomes the condition both for an effective relationship with God, and for a relation of the individual to himself. This alterity is understood by Kierkegaard as a teleological suspension and subsequently a re-signification of the categories as morality, duty and divine. The politician, from a Hegelian perspective, crosses this relationship with the general, and for this very reason, is coveted by the project of teleological suspension of Soren Kierkegaard. Teleological suspension which for the Danish philosopher is recognized as irony. To do so, in the determination of his concept of irony, he evokes the personality of Socrates. A punctual designation of the ironic relationship between such personality with the state and the political is inevitable. The personality of Socrates thus ironically evokes an opposition not only between objectivity and subjectivity, exterior and interior, but also between the social as a spontaneous and occasional relationship between individuals and the politician as an instrument of cohesion for the formation of the multitude. Starting from the relation between Socrates and the Greek State, pointed out by Kierkegaard as ironic, and recognizing in this relation a teleological suspension, the present work seeks to establish the criteria indicated by Kierkegaard for such determination.
\end{abstract}

Keywords: Kierkegaard. Irony. Teleological suspension. Morality. Hegel. 


\section{Apresentação:}

Segundo Álvaro Valls (1991 apud KIERKEGAARD, 1991, p.10) 0 Conceito de ironia, dissertação de 1841, constitui o plano geral ainda em progresso de amadurecimento, dos principais elementos temáticos e metodológicos de toda a obra do filósofo dinamarquês Soren Kierkegaard. É, portanto, endossado como o "método" ou a plataforma que nos permite conjecturar intensões e estabelecer o desenvolvimento de algumas interpretações, tais como as polêmicas desenvolvidas pelo filósofo ao longo de toda a sua obra. Sendo assim, é natural encontrarmos nela posicionamentos que reverberam tanto em sua obra heteronímica quanto veronímica.

Dentre elas, Temor e Tremor (1843), heteronímica, atribuída a Johannes de Silentio. Destaca-se em tal obra, uma original e provocante análise da narrativa bíblica do sacrifício de Isaque por Abraão (Cf. Gn.22) e suas implicações morais². No contexto, relações entre fé e moral, cultura e loucura, razão e ironia são avaliadas, a partir do pseudônimo de alguém que julga compreender bem a fé de Abrãa, contudo, é incapaz de aderir a ela, mediante ao que exige. É essa exigência que nos interesse como objeto para a presente pesquisa, que em princípio, aproxima Abraão de Sócrates, e posteriormente os separa. Por essa razão torna-se oportuna a relação entra as duas obras citadas e como suas problemáticas principais se relacionam.

\footnotetext{
${ }^{2}$ No contexto, partindo de um pressuposto hegeliano, não há uma distinção entre moral e ética, mas sim entre moral sobjetiva e moral objetiva.
} 


\section{Conceito de Ironia:}

0 conceito de ironia (1841) possui como orientação geral a determinação conceitual da ironia socrática por intermédio prévio da instituição de sua personalidade histórica. 0 problema consiste na disparidade dos relatos disponíveis ${ }^{3}$, que tornam problemática uma determinação universal e objetiva. Kierkegaard por sua vez, compreende tal dificuldade como o caminho determinante para "uma concepção (opfattelse) confiável e autêntica da existência (Existents) historicamente real, fenomenológica de Sócrates" (KIERKEGAARD, 1991, p. 23). Posição tomada a partir de um diálogo com a dialética hegeliana.

0 pressuposto para tal determinação possui forte inspiração na dialética hegeliana, contudo com diferenças bem específicas. Hegel e Kierkegaard concordam que o conceito é a mediação, contudo, se para o primeiro a mediação tem em vista a Ideia, para o segundo, constitui uma exigência que a mediação leve em consideração o fenômeno. Pois enquanto Hegel descarta o histórico na participação da Ideia, Kierkegaard por sua vez descarta a Ideia na participação do histórico. Para o primeiro se destaca 0 universal e 0 absoluto, para 0 segundo o histórico e 0 particular. Pois para Hegel "o que se desenvolve sobre bases históricas não pode se confundir com o desenvolvimento a partir do conceito, nem a legitimação e explicação históricas atingem jamais o alcance de uma justificação em si e para si" (HEGEL, 1997, p. 5). Enquanto que para Kierkegaard "se bem que o observador traga o conceito consigo, importa, mesmo assim, que o fenômeno não seja violentado e se veja o conceito surgindo a partir do fenômeno" (KIERKEGAARD, 1991, p. 23).

\footnotetext{
${ }^{3}$ Kierkegaard analisa os relatos disponíveis de Xenofontes e Platão (ambos discípulos de Sócrates que compõem apologias depois de sua morte) e de Aristófanes (comediante grego, autor de uma peça ridicularizando o filósofo grego).
}

\section{Blucher}


Para Kierkegaard a disparidade dos relatos disponíveis indica muito mais um ponto de vista do que uma determinação objetiva, enquanto que para Hegel seriam elementos descartáveis na determinação da Idéia. Enquanto ponto de vista, expressa uma composição, de modo a acrescentar na personalidade socrática a determinação positiva que escapava a todos. Por esse princípio Xenofonte endossa a empiria e Platão a Idéia. Aristófanes, por intermédio da comédia, expressa a ambiguidade, que para Kierkegaard mais se aproximou do conteúdo negativo que a própria ironia de Sócrates representava.

Ironia portanto, que não deve ser reconhecida como um simples instrumento retórico de convencimento, mas o inverso disso, posição existencial cuja ambiguidade expressa confusão, mal entendido, que segundo Kierkegaard, não se supera. Condição que define a ironia como negativo, o irônico como "subjetividade egoisticamente encerrada em si mesma" (KIERKEGAARD, 1991, p. 123) e por isso mesma, que torna a personalidade histórica de Sócrates incompreensível por seus contemporâneos e depois deles, para os seus intérpretes românticos.

Temor e Tremor ${ }^{4}$ por sua vez possui uma estrutura bem próxima ao Conceito de Ironia. Estabelece como orientação geral a determinação da fé de Abraão, isto é, de sua subjetividade, por intermédio prévio da eliminação das possibilidades positivas, universais e objetivas, que fariam "de um crime um ato santo e agradável a Deus, paradoxo que devolve a Abraão o seu filho, paradoxo que não pode reduzir-se a nenhum raciocínio, porque a fé começa precisamente onde acaba a razão" (KIERKEGAARD, 1974, p. 282). A relação entre uma obra e outra também não é

\footnotetext{
${ }^{4}$ Segundo Gouvêa, deve-se levar em consideração que Temor e Tremor, escrito pelo pseudônimo de Johannes de Silentio em 1843, não é um cristão, porém, alguém que entendendo a profundidade da vida na fé sente-se incapaz de ir adiante. É o estágio denominado ético religioso ou religiosidade $\mathrm{A}$.
} 
ocasional. Se por um lado, identifica Sócrates com Abraão, na posição de que nenhum conteúdo positivo pode enfim superar o paradoxo que define tanto a tarefa socrática de indagar seu contemporâneos, quanto de Abraão de imolar o filho que tanto ama, por outro lado, os separa radicalmente na intensão em determinar uma diferença qualitativa entre socratismo e a fé de Abraão, de maneira que a ironia as aproximam, mas a fé as separam.

\section{Suspensão Teleológica do Geral:}

Sócrates e Abraão se identificam quando a possibilidade da tarefa implica o paradoxo. Se distinguem porém qualitativamente no que o paradoxo exige ${ }^{5}$. Paradoxo que implica uma suspensão teleológica do geral. 0 geral constitui a grande obsessão da filosofia do direito de Hegel. Inspirado em Platão, Hegel entende que a filosofia trata especificamente de Idéias. 0 conceito portanto, constitui a mediação necessária à realização das formas abstratas. A Idéia corresponde a manifestação do conceito (HEGEL, 1997, p.1) na objetividade, pois "na objetividade reside a verdade da certeza" (HEGEL, 1997, p.148). A objetividade constitui a identidade entre 0 universal e o particular. É nesse sentido que Hegel distingue uma moral objetiva de uma moral subjetiva, sendo esta última ao que não é idêntico pois "Com efeito, o desejo de ser algo de particular não se adequa ao universal em si e para si. Só na exceção se encontra a consciência da singularidade" (HEGEL, 1997, p. 145). Posição que deve ser suprimida na teleologia da

\footnotetext{
${ }^{5}$ Pois a partir dai há categorias que o grego não contempla, como pecado e graça. 0 paradoxo, para o grego limita-se então ao terreno moral, no dever para consigo. Para o cristão porém, impõe o dever para com Deus.
}

\section{Blucher}


moralidade, segundo o filósofo alemão, pois "o caráter moral objetivo conhece que seu fim motor é o universal, imutável se bem que aberto em suas determinações à racionalidade real, e reconhece que a sua dignidade, assim como tudo o que na existência assegura os seus fins particulares, se funda neste universal onde realmente os encontra" (HEGEL, 1997, p. 147).

Para Hegel, a substância universal da moral objetiva é consagrada na vida pública (HEGEL, 1997, p. 149), que segundo ele constitui "o Espírito real de uma família ou de um povo" (HEGEL, 1997, p. 148). As etapas ou o movimento executado pelo conceito em direção a essa idéia atravessam o espírito moral objetivo imediato através da família, sociedade civil e por fim, do Estado. 0 Estado é portanto "a realidade em ato da Idéia moral objetiva" (HEGEL, 1997, p. 216).

É se referindo à moral objetiva hegeliana que Johannes de Silentio compreende a moral como situada no geral, aplicável a todos, a todo instante ${ }^{6}$. Participando "da mesma natureza da eterna felicidade do homem" (KIERKEGAARD, 1974, p. 283) a moralidade compreende assim uma identidade teleológica com 0 divino (KIERKEGAARD, 1974, p. 292). Negar essa posição da moralidade corresponde em afirmar que esta mesma pode ser ideologicamente suspensa ${ }^{7}$. Negação estabelecida por uma crise que exige a reintegração do indivíduo no geral, o que significa perder-se como indivíduo, ou a suspensão do geral tendo em vista seu telos no divino. Posições que não se equivalem pois "estar suspenso não significa perder-se, mas conservar-se na esfera superior que é o seu telos" (KIERKEGAARD, 1974, p. 283), o que na perspectiva hegeliana

\footnotetext{
${ }^{6}$ Entretanto, cabe ressaltar, Johannes não é um hegeliano, mas alguém que entendeu Hegel, e vê no cristianismo sua superação imediata, contudo, não tem a coragem necessária para realizar o movimento de um ao outro.

${ }^{7}$ Há uma evidente distinção entre fé e moral no postulado. Postura oriunda da fé luterana em suas origens.
} 
equivaleria a uma "forma ética do mal, ou seja, expressão do particular no geral" (KIERKEGAARD, 1974, р.. 283).

0 Indivíduo quem, depois de ter estado como tal subordinado ao geral, alcança ser agora, graças ao geral, o Indivíduo, e como tal superior a este; de maneira que o Indivíduo como tal encontra-se numa relação absoluta com 0 absoluto. Esta posição escapa à mediação que se efetua sempre em virtude do geral. Ela é e permanece eternamente um paradoxo inacessível ao pensamento (KIERKEGAARD. Soren. 1974. Pag. 284)

A suspensão teleológica do geral corresponde a uma "reivindicação da individualidade, depois deste mesmo indivíduo ter entrado no geral" (KIERKEGAARD, 1974, p. 283), isto significa, participando de todas as etapas pelos quais a moral objetiva se torna realidade em ato. Tornar-se indivíduo a partir do movimento de perder-se como tal no geral. Ora, não participa a ironia socrática do mesmo processo quando o filósofo grego infere para si isolação pessoal? Não corresponderia em crime contra o Estado justamente a condução de outros tantos a mesma expressão particular no geral? Não seria isso mesmo o mal numa perspectiva hegeliana? Bastariam os gregos então para explicar Abraão como um recorrente caso de ironia? Sócrates poderia, ao lançar um indivíduo para fora da realidade do Estado, torna-lo um ironista como ele (embora permanecesse um mistério), por outro lado, ninguém pode imitar Abraão, o que o torna impossível de ser pensado, repetido.

Se por um lado a fé exige aquela mesma suspensão teleológica do geral tão próxima à ironia socrática, por outro lado, evoca de igual maneira uma distância radical. Pois os gregos não conhecem as categorias de pecado e fé, sendo por isso mesmo o geral reconhecido como divino e

\section{Blucher}


a reivindicação de individualidade de Sócrates ser legítima como um mal em seu contexto. 0 que torna Hegel um bom interprete dos gregos nesse sentido, mas não da fé de Abraão e do cristianismo.

A moralidade, em si, está no geral, e a este título é aplicável a todos. 0 que pode por outro lado, exprimir-se dizendo que é aplicável a cada instante. Repousa imanente em si mesma, sem nada exterior que seja o seu telos sendo ela mesma telos de tudo o que lhe é exterior; e uma vez que se tenha integrado nesse exterior não vai mais além. Tomado como ser imediato, sensível e psíquico, o Indivíduo é o Indivíduo que tem o seu telos no geral; a sua tarefa moral consiste em exprimir-se constantemente, em despojar-se do seu caráter individual para alcançar a generalidade (KIERKEGAARD. Soren. 1974. Pág. 283).

A ironia socrática corresponde a um ponto de vista negativo frente a qualquer positividade, o que inclui o Estado e o exercício objetivo do poder, no qual sua personalidade recusava integrar-se. Como consequência, sua visão subjetiva, ironicamente situava-se contra a soberania do povo e o julgamento objetivo do Estado, de maneira que sua condenação a morte não representava nenhuma realidade, pois "Sócrates não sabe simplesmente nada, e neste sentido é uma ironia sobre o Estado, que o condena a perder a vida, e com isso crê que o puniu" (KIERKEGAARD. Soren. 1991. Pág. 235). Sua missão divina de indagar seus contemporâneos the privava de tempo e oportunidade para dedicar-se ao Estado, a família e outros assuntos de caráter público (KIERKEGAARD. 1991. Pág. 141). Deslocava-se assim da posição de cidadão e sua ação não poderia por isso receber no âmbito público uma qualificação ou predicado de qualquer espécie. Era um homem sem títulos (KIERKEGAARD. 1991. Pág.142). 0 embate com o Estado ocorre não pela decisão de Sócrates em viver como um homem privado, mas sim por induzir outros 
tantos a lançarem-se para fora da realidade pública como ele, configurando o crime de tornar 0 Estado ausente daquela mesma substancialidade que somente pode ser conferida a ele por intermédio da adesão à tradição.

Por outro lado, Kierkegaard reconhece que muito embora a ironia não tenha como orientação a suspensão da realidade como um todo, mas sim da realidade dada a uma certa época, configura-se em nosso tempo, de afirmação de uma certa subjetividade positiva e de um espírito democrático estranho ao Estado grego, uma nova tarefa para aquela mesma ironia que a tudo esvaziava de conteúdo.

Se se levar em conta que mesmo em nossos países, quando o Estado, justamente porque atravessou uma mediação muito mais profunda, já reconhece à subjetividade um espaço completamente diferente, muito mais do que o Estado grego era capaz de fazer, se mesmo aí, digo eu, em nossos Estados, um "particular" continua a ser uma pessoa ambígua, então se poderá daí deduzir com que olhos o Estado grego deve ter considerado a tentativa de Sócrates de andar o seu caminho por conta própria e levar a vida como um homem privado (KIERKEGAARD. 1991. Pág. 141).

É nesse sentido que o empenho socrático não se encontra limitado a uma específica realidade dada no passado, mas nos alcança enquanto tarefa a ser executada diante do paradoxo determinado em nosso próprio tempo. Sócrates não é um homem de partido. Sua ironia impulsiona a cisão que garante a liberdade necessária à indiferença ao pathos cívico e aos interesses do Estado, por outro lado, dedica-se apaixonadamente a sua missão de conversação, isolação pessoal e ao trato com todos os homens, que para ele representavam, situados nas mais diversas representações sociais, apenas uma soma de indivíduos. Seu interesse pelo indivíduo o

\section{Blucher}


situava acima dos interesses partidários que garantem a manutenção do poder. Por outro lado, não há qualquer conteúdo conquistado por essa relação, pelo contrário, dele todo conteúdo é privado, determinando assim todo o processo de conquista de si mesmo.

E quanto mais ele se mostrava inflexível em não se submeter ao Estado, tanto mais flexível, tanto mais maleável ele era no trato com os homens, tanto maior virtuose dos encontros casuais. Ele gostava igualmente de falar com agricultores, alfaiates, sofistas, homens do Estado, poetas, com jovens e velhos, falava facilmente sobre todos os assuntos, porque em toda parte encontrava uma tarefa para sua ironia. Mas em tudo isso não era certamente um bom cidadão e certamente não tornava melhores cidadãos os outros. Se o ponto de vista de Sócrates era realmente superior ao do Estado, se ele em verdade estava autorizado pela divindade, sobre isto a história universal deve julgar, mas se ela deve julgar razoavelmente, então tem de conceder ao mesmo tempo que 0 Estado estava autorizado a condenar Sócrates. Num certo sentido, ele era, portanto, revolucionário, contudo não tanto ao fazer alguma coisa quanto ao se omitir de fazer algo; mas homem de partido ou cabeça de um complô ele não era, disto o preservava a ironia; pois assim como esta o privava da verdadeira simpatia do cidadão pelo Estado, do verdadeiro "pathos" cívico, também 0 livrava daquela morbidez e daquela exaltação que é condição para um homem de partido. Sua posição era por demais a de uma isolação pessoal (KIERKEGAARD. Soren. 1991. Págs. 142-143).

\section{Ironia, Razão e Paixão Religiosa:}

Sendo o geral aplicável a todos a todo instante (KIERKEGARR. 1974. Pág. 283), é exigido dele um constante movimento de repetição, o que significa, a exigência permanente do particular, tendo como tarefa moral, despojar-se constantemente de seu caráter individual em vista da generalidade. Movimento que paradoxalmente constitui a possibilidade de suspensão 
dessa generalidade, quando o Indivíduo "reivindica a sua individualidade frente ao geral" (KIERKEGAARD. 1974. Pág. 283). Por sua vez, reivindicar essa individualidade constitui de igual maneira uma repetição, que para tanto exige um movimento em direção ao geral. A moralidade, assim como a fé, se correspondem no permanente movimento de integração no geral e isolação pessoal. Movimento que indica uma suspensão, seja do indivíduo (constituindo a moralidade), seja da moralidade (constituindo a fé). A correspondência se estabelece pelo movimento, por outro lado, se distinguem pelo telos. A moralidade enquanto telos da individualidade exige 0 constante despojamento desta última, assim como, a individualidade assumida como telos exige o constante despojamento da generalidade, posto que "a fé é esse paradoxo segundo o qual o Indivíduo está acima do geral, mas de tal maneira que, e isso importa, o movimento se repita e, por consequência, o Indivíduo, depois de ter permanecido no geral, se isole logo a seguir, como Indivíduo acima do geral" (KIERKEGAARD. 1974. Pág. 283).

0 constante movimento de repetição exige uma suspensão que se identifica ao irônico. Constitui uma suspensão, posto que "estar suspenso não significa perder-se, mas conservar-se na esfera superior que é o seu telos" (KIERKEGAARD. 1971. Pág. 283). Suspensão que é ironia e que se distingue quantitativamente e qualitativamente pela natureza do movimento exercido: a suspensão do individual tendo em vista o geral, compreende a ironia em seu sentido retórico, comum, que se dedica a suspensão de casos particulares. Por outro lado, a suspensão do geral tendo em vista o individual, compreende a ironia em seu sentido filosófico, existencial, identificada de maneira paradigmática na figura socrática.

\section{Blucher}


A diferença entre todas essas manifestações de ironia até aqui mencionadas é portanto apenas quantitativa, um mais ou menos, enquanto a ironia sensu eminentiori (no sentido mais elevado, mais próprio) se diferencia qualitativamente da ironia até aqui descrita, assim como a dúvida especulativa se diferencia qualitativamente da dúvida vulgar e empírica. A ironia sensu eminentiori não se dirige contra este ou aquele existente individual, ela se dirige contra toda a realidade dada em uma certa época e sob certas condições (KIERKEGAARD. 1991. Pág. 221).

No âmbito alegórico, o movimento de suspensão do geral em direção ao particular, é tipificado poeticamente por Johannes de Silentio através da figura do bailarino, que ergue-se do chão por um salto, e com perfeita habilidade, elegantemente pousa no chão, mesmo quando não consegue se equilibrar completamente, retorna continuamente o movimento.

Imagino que, para um bailarino, o esforço mais difícil consiste em colocar-se, de um só golpe, na posição precisa, sem um segundo de hesitação. É possível que não exista um acrobata com tal habilidade e domínio: tem-na porém o meu cavaleiro. Muitos homens dominados pelos cuidados e prazeres do mundo: assemelham-se àqueles que vão à festa sem dançar. Os cavaleiros do infinito são bailarinos a quem não falta elevação. Saltam no ar e logo voltam a cair, o que não deixa de constituir passatempo divertido e nada desagradável à vista. Mas de cada vez que recaem não podem, logo no primeiro momento, guardar completo equilíbrio. Por instantes vacilam indecisos, o que logo mostra que são estranhos ao mundo (...). Voltar porém a cair de tal modo que se dê a impressão do êxtase e da marcha ao mesmo tempo; transformar em andamento o passo normal do salto; exprimir o impulso sublime num passo terreno; eis o único prodígio de que só é capaz o cavaleiro da fé(KIERKEGAARD; 1974. Pag.274). 
0 cavaleiro da fé, ao realizar o movimento de suspensão teleológica da moral, identificase ao irônico, "é expressão do supremo egoísmo: realiza o terrificante, realiza-o por amor de si próprio" (KIERKEGAARD. 1974. Pág. 294), entretanto, paradoxalmente distingue-se dele por executar seu movimento a partir da categoria do pecado e do dever para com Deus "por outro lado é a expressão do mais absoluto abandono, atua por amor de Deus". (KIERKEGAARD. 1974. Pág. 294). A ironia enquanto categoria existencial qualifica-se então a partir de um patamar filosófico com Sócrates e outro, religioso, com Abraão. Distinguem-se dessa maneira, pois enquanto Sócrates exige sua individualidade diante do geral, Abraão por sua vez, não apenas a exige diante do geral, mas também de uma instância superior a ele e por isso o religioso é indicado por Johannes de Silentio como uma instância acima, pois atravessa aquela mesma dimensão da existência onde se torna impossível falar. Existência singular.

Gouvêa muito bem esclarece, que a intensão de Kierkegaard através de seu pseudônimo Johannes de Silentio consiste em "falar sobre a relação entre fé e razão, e de apresentar Abraão como o 'cavaleiro da fé', modelo maior de vida de fé em virtude do 'absurdo' (do paradoxo), e explicar, em oposição ao hegelianismo, por que a fé não é inferior à razão, mas sim um dom superior e espetacular, um longo e duro aprendizado, uma paixão feliz, uma divina loucura, e um complexo 'movimento duplo' do espírito humano" ( GOUVÊA. 2000. Pág. 234).

\section{Conclusão:}

A moral, compreendendo o movimento do indivíduo ao geral, pressupõe a exceção quando 0 indivíduo, depois de integrar-se a generalidade, reivindicando sua individualidade,

\section{Blucher}


realiza o movimento inverso. A generalidade é por sua vez teleologicamente suspensa. Posição que pode ser determinada como ironia ou fé, que se distinguem qualitativamente pelas categorias presentes nesta última do pecado e da graça, mas que se identificam enquanto negativo que a tudo esvazia de conteúdo, paradoxo. A fé exige ironia, aquela mesma disposição de espírito à singularização, que os gregos concebiam como um mal, desagregando os homens da vida pública e motivando-os ao permanente cultivo da vida interior. A ironia por outro lado, enquanto condição prévia, nada pode exigir da fé. Abraão vai mais longe que Sócrates.

Um dos dilemas mais engraçados no exercício do poder, e particularmente hoje, com a democracia, consiste justamente em acreditar que qualquer um pode estar à espreita e ser potencialmente o próximo governante. Postura que inibe de indiferença e inflamam os ânimos das massas, tornando toda e qualquer posição política individual digna de relevância, de amizade ou inimizade. Posição bem característica de certo arcaísmo hegeliano que torna a vida pública a consumação da moral em sua objetividade, e o Estado, manifestação em ato desta Idéia.

Segundo Kierkegaard, Sócrates por outro lado, se recusa com sua ironia a ser um homem de partido. Postura inversamente proporcional ao seu interesse pelo indivíduo, independente de sua posição social e ideologia. Tornar-se pois indivíduo constitui, ontem e hoje, a tarefa por excelência que muito embora relegue à indiferença os diversos instrumentos de coesão social tornam mais flexíveis as relações humanas, pois implica olhar o outra, de igual maneira como indivíduo, individualmente. 


\section{Referências Bibliográficas:}

GOUVÊA. Ricardo Quadros. Paixão pelo Paradoxo: uma introdução aos estudos de Soren Kierkegaard e de sua concepção de fé cristã. Ed. Novo Século. 2000.

HEGEL. Georg Wilhelm Friedrich. Princípios da Filosofia do Direito. Ed. Martins Fontes. 1997.

KIERKEGAARD. Soren. O Conceito de Ironia, constantemente referido a Sócrates. Ed. Vozes. 1991. Temor e Tremor. Coleção "Os Pensadores". Ed. Abril Cultural. 1974. 